\title{
The Evidential Value of Near-Death Experiences for Belief in Life After Death
}

\author{
Michael Potts, Ph.D. \\ Methodist College, Fayetteville, NC
}

\begin{abstract}
$A B S T R A C T$ : In this paper, I explore the issue of what evidential value neardeath experiences (NDEs) offer for belief in life after death. I survey the major positions on this issue, ranging from writers who believe that NDEs already offer convincing evidence for life after death, to physicalists who believe that they offer, at best, a very weak case. I argue that the present NDE evidence does suggest the possibility of life after death; however, such evidence is not yet overpowering or convincing. However, I go on to argue that NDEs do offer persuasive evidence for life after death for the individual who has the NDE. I end by suggesting that further research should be done on the most impressive type of NDE evidence for life after death, veridical perceptions during an NDE.
\end{abstract}

KEY WORDS: near-death experience; out-of-body experience; evidence for survival.

Since the publication of Raymond Moody's Life After Life (1975), there has been a plethora of literature on so-called "near-death experiences" (NDEs). In such experiences, some individuals who have been resuscitated from cardiac arrest report a sense of separation from the body and experiences that occur during that period of separation. The phenomena reported include viewing one's body, observing its resuscitation, moving in a tunnel towards a light, visions of dead relatives, and visions of religious figures such as Jesus Christ. In order to classify the different sorts of experiences associated with this phenomena, Michael Sabom (1982) has proposed a useful distinction between "autoscopic" and "transcendental" NDEs. The autoscopic NDE involves a sense of

Michael Potts, Ph.D., is Associate Professor of Philosophy at Methodist College in Fayetteville, NC. Reprint requests should be addressed to Dr. Potts at Methodist College, 5400 Ramsey Street, Fayetteville, NC 28311-1420; e-mail: mpotts20@hotmail.com. 
separation from the body and may include seeing one's physical body, as well as seeing and hearing one's resuscitation. The transcendental NDE involves visions of "another world," including experiences of religious figures, such as angels or God.

Among the philosophical issues raised by NDEs is what evidential value, if any, they offer for belief in God, divine beings, life after death, or simply some form of survival after death. Individuals who experience NDEs almost invariably are convinced that their experiences were of objective reality; NDEs have, as do mystical experiences, what William James (1902/1958) called a "noetic quality." Could NDEs serve to make a convincing case for the existence of God or angels or life after death? Strangely enough, as Emily Cook, Bruce Greyson, and Ian Stevenson (1998) noted, those who investigate NDEs "have with rare exceptions completely ignored the question of the survival of consciousness after the death of the body" (p. 378), while those who investigate whether the self survives after death "have shied away from NDEs, judging that they offer little promise of yielding convincing data bearing on the survival question" (p. 378), because NDEs are subjective experiences, and the perceptions that occur during NDEs are difficult to verify. Although the issue of NDE evidence for life after death has been discussed more in recent years, further study needs to be done.

This paper focuses on the issue of what evidential value, if any, NDEs offer for belief in life after death. By "life after death," I mean some conscious experience and perception after death; this does not necessarily refer to unending life after death. I will survey the major positions on this issue, ranging from writers who hold that NDEs already offer strong evidence for life after death to those writers who believe that they offer a very weak case for survival. First, I examine the position of Gary Habermas and J. P. Moreland (1992), who believe that NDEs offer strong evidence for a minimal life after death which includes survival of a personal, nonphysical soul. Their position represents one extreme on this issue and is thus a useful starting point for further discussion. I will argue that their position goes beyond the available evidence. I will then discuss positions that, although denying Habermas and Moreland's position that NDEs offer convincing evidence of survival of death, hold that NDEs are pointers suggesting the possibility of some kind of postmortem survival.

In the next section, I will discuss the physicalist position on NDEs, which holds that they can be exhaustively explained in terms of physiological processes in the dying body and offer, at best, very weak evidence for an afterlife. I will discuss some characteristic physicalist 
interpretations of NDEs, such as the position that NDEs occur due to physiological processes similar to drug-induced experiences. Much of the discussion will center on the work of Susan Blackmore (1993), who holds that NDEs can be explained totally in terms of physiological processes within the body at the point of death. According to Blackmore, NDEs may have psychological value for the individual; however, they do not provide strong evidence for life after death since they can be exhaustively explained neurophysiologically. Although acknowledging the strength of the case developed by Blackmore and other physicalists, I argue that they unnecessarily rule out nonphysicalistic explanations, and that it is possible that future evidence from NDEs could provide a stronger case for life after death.

In the final section, I offer an alternative to both positions. Agreeing with the more nuanced and careful position of writers such as David Lorimer (1984), Paul and Linda Badham (1982), and Carl Becker (1993, 1995 ), I will argue that, given present evidence, NDEs offer some public evidence for life after death, but more along the lines of suggestions or pointers for further research. Given further research, these pointers have the potential to produce a strong case for life after death based on the NDE evidence. However, I further argue that an NDE can offer reasonable, even strong, evidence for life after death for the individual who has the NDE. As an example, I discuss the case of Pam Reynolds (Sabom, 1998), who had perceptions, during a time of no cardiopulmonary or brain function, that are difficult to explain apart from the notion that she had some perception separate from her body. Those perceptions, combined with her perceptions of deceased relatives, do, in my judgment, make it reasonable for Reynolds to believe that she had an experience of a "minimal" life after death. But at this stage of the game, without further study, such perceptions do not yet offer convincing evidence for life after death for those who have not had NDEs. Finally, I will discuss a recent study by Sam Parnia, D. G. Waller, R. Yeates, and Peter Fenwick (2001), which represents a promising direction for further study on potential NDE evidence for survival of death.

\section{The Case That NDEs Provide Strong Evidence of Survival}

Habermas and Moreland argued for the position that NDEs are "strong evidence for at least a minimalistic view of life after death," which they defined as "life in the initial moments after death, not some 
detailed version of heavenly life or even necessarily eternal life" (1992, p. 74). They distinguished "between clinical (or reversible) death and biological (or irreversible) death" (p. 73). Clinical death occurs when there is loss of vital signs such as "consciousness, pulse, and breathing" and is potentially reversible; if it is not reversed, it leads to biological death, which is "physically irreversible." The authors, following Moody, added a third category "between these two," a patient with a flat electroencephalogram (EEG), that is, no electrical brain waves.

Habermas and Moreland argued that four types of evidence converge to make a strong case that NDEs should be interpreted as experiences after death. First, they referred to cases in which people near death, including some clinically dead, describe their surroundings in accurate detail. They summarized a number of cases, including one taken from Melvin Morse's book on the NDEs of children (Morse and Perry, 1990), that of a young girl who almost drowned in a pool. She was later able to describe the physical characteristics of the doctors involved in her resuscitation, details of the hospital rooms into which she was taken, and specific details concerning medical procedures used during her resuscitation. Habermas and Moreland also referred to cases of blind persons (not persons congenitally blind, but persons who became blind later in life) who reported visual details of the people surrounding them in their near-death state. Such specific visual details of the patients' resuscitations suggest some form of separation of the "soul" from the body, which in turn suggest survival of the self in some form after clinical death.

Habermas and Moreland's "second line" of evidence probably should not be listed as a separate category. It is simply the fact that many people who have given such accurate details concerning their resuscitations were experiencing cardiac arrest at the time; Habermas and Moreland referred to Sabom's study (1982) that analyzed the responses to a questionnaire concerning the procedure of resuscitation from cardiac arrest. The questionnaire was given to victims of cardiac arrest who had experienced NDEs and also to 25 cardiac patients who had not. It is important to note although all of Sabom's 25 comparison subjects were chronic cardiac patients, only four had suffered cardiac arrest without an NDE. The responses of those who had NDEs were much more accurate and detailed concerning the procedure of resuscitation than those who did not have a NDE.

The third line of evidence is from patients who had flat EEG readings. Some of these patients reported experiences that apparently occurred during this time of isoelectric EEG activity. Habermas and Moreland claimed that "presently the absence of any EEG brain wave function 
is the best and most widely accepted indication that the brain is not functioning" (p. 77). As noted below, this claim is inaccurate. They presented an anecdotal case (taken from Kübler-Ross, 1976) of a woman who was declared dead with no vital signs and a flat EEG who regained consciousness three and one-half hours after being pronounced dead. She revived while being taken to the morgue and accurately described her resuscitation.

The fourth line of evidence Habermas and Moreland presented consists of cases in which NDErs had visions of loved ones who had died, but whom the NDEr did not previously know had died. This provides evidence for the position that consciousness continues even after biological death, in the case of the deceased loved ones seen during the NDE. From these lines of evidence Habermas and Moreland concluded that NDEs provide strong evidence for consciousness continuing when the brain is not functioning, and that this in turn provides strong evidence "of minimalistic life that exists at that moment after death" (p. 84, italics original).

Although the case presented by Habermas and Moreland has some force, it does not succeed, at least at this point, in presenting a strong argument for a "minimalist life after death." First, although they did refer to Sabom's statistical research on NDEs, they also quoted from a number of sources, such as the writings of Maurice Rawlings (1980) and Elisabeth Kübler-Ross (1976), that referred to anecdotal cases. Such sources lack the careful research and data gathering found in Sabom's study. Habermas and Moreland replied that there is nothing wrong with using interviews to gain information; after all, historians do the same. This is fair enough, but such interviewing should be done well, under as controlled conditions as possible. Many anecdotal reports of NDEs remain just that-anecdotal-because they lack any evidence of a careful attempt to interview all the parties involved in a patient's resuscitation to check the accuracy of the NDEr's report.

There are even more serious difficulties with Habermas and Moreland's case. The claim that a flat EEG is sufficient to diagnose a lack of brain activity is simply false, because the EEG only registers activity on the surface of the cerebral cortex. It is possible that activity continues in other sections of the brain (McCullagh, 1993). There are also, as Habermas and Moreland recognized, alternative explanations for NDE phenomena, including drugs and anoxia, or lack of oxygen to the brain. Although one naturalistic explanation may not adequately explain a particular NDE, it is possible that a combination of naturalistic explanations may be able to explain every NDE. Plus, physicalist 
explanations, which do not refer to a disembodied soul, are more parsimonious than nonphysicalist explanations.

Evidence that supports a physicialist explanation of NDEs includes NDE-like experiences that occur when a person is not near death. A number of drug-induced experiences induced by drugs such as ketamine (Jansen, 1997) and "fear-death" experiences (Owens, Cook, and Stevenson, 1990) that occur when a person is in serious danger, but not near death, mimic NDEs (Noyes, 1972; Noyes and Kletti, 1976; Blackmore, 1993). Some people who do not have health problems and who are not in any immediate danger have reported out-of-body experiences (OBEs) through meditation; sometimes they even occur spontaneously. And as Habermas and Moreland themselves noted, Wilder Penfield invoked NDE-like experiences in his patients by stimulating the temporal lobe of the brain (Penfield and Rasmussen, 1950), which suggests that NDE-like experiences are correlated with changes in brain physiology; and it is a reasonable position to hold that such experiences are caused by the physiological changes.

As impressive as the evidence from Sabom's study is, it is not enough to support the strong evidentialist conclusion of Habermas and Moreland. As already noted, his comparison group did not consist primarily of patients who had experienced cardiac arrest and resuscitation; as Blackmore pointed out, it was not a good control group. (I will discuss her case against Sabom in more detail below.) Further study is needed to corroborate Sabom's results. Even if NDErs do present evidence that they had sensory experience of their resuscitation, this does not necessarily imply a nonphysiological explanation. Other explanations are possible, including forming false memories from hearing things during the resuscitation, or from hearing about the resuscitation later from healthcare professionals or family members.

V. Krishnan (1985) offered a further critique of Sabom's evidence. Krishnan recognized Sabom's claim that some NDErs experience "clear and accurate visual perception" (p. 23). Yet Krishnan did not agree with Sabom's interpretation, partly because the position from which NDErs claim to observe is "nearly always above the level of the body when the experience occurs spontaneously and for the first time" (p. 23). This has even been true in "fear-death" experiences, which may occur, for example, in a person falling from a great height. Krishnan wrote about this point:

If the mediator of out-of-body vision is an element that functions independently of the body, I find no reason why it should position itself only 
above the body; it seems reasonable to expect instances of observation of oneself from other positions to be no less frequent. For example, in the case of a person undergoing an OBE when sitting or standing or falling from a height, self-observation is possible from the front at eye-level or below it. (1985, p. 23)

Of course there is no a priori reason why NDErs should not view their bodies from the same position; in addition, at times NDErs have the experience of moving away from their bodies into other rooms or even outside a building. I will discuss Krishnan's skeptical case against the survivalist interpretation of NDEs further below. These criticisms are insufficient to show that research such as Sabom's does not offer genuine evidence for survival of death. Sabom's evidence should be taken very seriously, especially regarding veridical perception in NDEs, but it is not yet strong enough, without further large scale studies, to support the claim that NDEs offer "strong evidence" of even a "minimalist" view of life after death.

\section{The Case That NDEs Provide Weak Evidence of Survival}

Other writers have seriously considered the positive evidence that NDEs support survival of death, but have been more nuanced and cautious in their evaluation of the evidence than Habermas and Moreland. Among these is Lorimer (1984), who viewed the evidence for life after death from a wide range of phenomena, not limited to near-death experiences, but also including out-of-body experiences (OBEs), reports of individuals who claim to remember their death in previous lives, and apparitions. Lorimer concluded:

the data surveyed are not in themselves coercive or conclusive proof that the conscious self survives bodily death; they are, nevertheless, concrete pointers which demand a coherent and comprehensive explanation. If reports of apparitions, OBEs, NDEs and death experiences are accepted as valid evidence, then materialistic theories of mind have only limited application-to normal processes in the explicate order of appearances.... [In the phenomenon of death] conscious experience may well be continuing in an enhanced state, released from the cramping confines of space-time, the physical body, and perhaps even the separate ego. (1984, p. 304)

Such phenomena as deathbed experiences are relevant to the issue of life after death, and OBEs are relevant to the issue of whether the 
self can have experiences independent of the body. There is room for researchers such as Lorimer to make use of a wide variety of phenomena to form a convergent case for survival after death. A detailed examination of such phenomena is outside the scope of this paper, which focuses primarily on the evidence relevant to life after death from NDEs, although other phenomena should be considered in a broad based survey of the evidence for life after death.

Badham and Badham (1982) did consider, along with the NDE evidence, $O B E$ research and evidence from deathbed visions of patients. Despite recognizing potential rivals to transcendental interpretations of NDEs, such as hallucinations or physiological factors, they remained impressed by Sabom's evidence of veridical perception during NDEs collected. However, they noted that even these might be explained in terms of prior knowledge of hospitals and resuscitation units, combined with auditory stimuli just before loss of consciousness. Taking a cue from recent $\mathrm{OBE}$ research, they suggested that a study be done in which recognizable figures were painted on the light fixtures in intensive care units, so that patients having NDEs would have to see these from above to identify them correctly. If that occurred, it would constitute strong evidence that some part of the human person can exist separate from the body and have veridical perceptions. Such perceptions are relevant to the issue of whether there is life after death:

Near-death experiences are therefore of the utmost importance to research in life after death, for the evidential features in the reports made by resuscitated persons about their supposed observations provide some of the strongest grounds for supposing that the separation of the self from the body is possible. (Badham and Badham, 1982, p. 78)

Badham and Badham then examined the NDE evidence in more detail and wrote that the strong conviction of NDErs that they have experienced life after death has at least some evidential force. They were not impressed with claims of visions of dead relatives, for there are more plausible explanations than an actual vision of the relatives, or as the case of a child who claims to recognize a dead relative seen in his or her vision when shown a photograph of the person, they "strain credulity." Why should the child have seen her relative at the exact same age and appearance as the person in the photo? Cases in which a NDEr sees, with surprise, relatives whom he or she did not know were dead have more evidential force. Badham and Badham were also impressed by the amount of crosscultural agreement between NDE 
accounts. There is, then, at least a "prima facie case ... for treating near-death experiences as evidence for the possibility of personal survival of bodily death" (p. 81), though this evidence is tempered by the possibility of alternative medical explanations, such as cerebral anoxia or the effects of drugs. In the end, despite concerns about the reliability of some NDE research, Paul Badham (his wife, Linda, was more skeptical about life after death in general) concluded that once alternative explanations are ruled out, the NDE evidence does give us grounds to believe that they are

reports of what actually happens at the moment of death. And what appears to happen is that the soul leaves the body and begins to move on to another mode of existence....

There is therefore at least some evidence to support the belief in the immortality of the soul through bodily death. (Badham and Badham, 1982 , p. 89)

While agreeing that NDEs offer some grounds for belief in survival of death, I am not convinced that the evidence from NDEs offers "some evidence to support the belief in the immortality of the soul." Even if the experiences are by a disembodied soul around the moment of death, this does not imply that the soul lives forever after death. At most, such evidence would support the view that there is some kind of body-independent experience after death. Whether the NDE is an experience of eternal life does not appear to be a question that can be answered by near-death research. Even so, if the evidence offers some grounds for belief in either bodily-independent experience or some kind of after-death experience, such evidence alone would be of considerable importance, for it would offer a significant challenge to contemporary physicalist interpretations of the human being.

Another writer who believes that NDEs offer some evidence for survival of death is Becker $(1993,1995)$, who surveyed a number of different types of paranormal experience, including hauntings, apparitions, OBEs, deathbed visions, and NDEs. In his discussion of NDEs, Becker attacked the position that, because NDErs were revived, they could not have been dead, calling that position "specious question-begging because it assumes as a fact the premise that no one ever revives the truly dead, which is precisely the issue in question" (Becker, 1993, p. 93). He asserted that if death is defined "in terms of brain activity, and someone has no brain activity but later reports experiences during that period, we have proof that conscious experience is possible after death, at least temporarily" (1993, p. 97). (This is a problematic claim, because part of 
the conception of death includes the notion of irreversibility, but I shall not argue for that position here.)

Becker then attacked reductionist claims that, since NDEs are like brain malfunctions, they must be "exhaustively described by them" (p. 99), an assertion that, Becker wrote, does not follow. First, experiences with drugs, OBEs, or experiences due to brain malfunction may still open the subject to another world. Second, there are differences between drug-induced experiences and NDEs; for example, far more NDErs (more than 80 percent) "had visions of dead friends and relatives" (p. 104) but only about 20 percent of those having drug induced experiences did. Becker attacked a number of other reductionist explanations of NDEs and held that NDEs as well as "claimed memories of past lives, apparitions and OBEs, and NDEs with paranormal visions" (p. 119) are best explained by the survivalist theory that the subject survives the death of the body.

Another generally positive, though cautious, analysis of the evidential value of NDEs is found in an article by Cook, Greyson, Stevenson (1998). They believe that three features of NDEs may offer "convergent evidence supporting the survival hypothesis": "enhanced mentation, the experience of seeing the physical body from a different position in space, and paranormal perceptions" (p. 377). "Enhanced mentation" refers to the heightened perception NDErs have during times in which they should not be having perceptions at all, much less heightened ones. Evidence of heightened perception combined with "diminished physiological functioning at least suggests that consciousness might not be so dependent on physiological processes as most scientists now assume" (p. 379). According to these authors, although crosscultural similarities between NDEs may be due to common physiological or psychological processes, still, enhanced mentation during an NDE offers at least some evidence for the mind's ability to function independently of the body.

Second, there is the sense NDErs have of being out of the body and viewing the body from a different position in space. Of course there are multiple alternative explanations to the hypothesis that the subject really is out of the body, for it is a subjective phenomenon. Present research on OBEs, including that on subjects not near death, has not conclusively shown evidence that an individual experiencing an OBE can perceive specific distant objects. Again, Cook, Greyson, and Stevenson (1998) suggest that the OBE phenomenon in the NDE offers some evidence for the survival hypothesis, but the evidence remains inconclusive. 
The most impressive evidence for the survival hypothesis, according to these authors, comes from paranormal perceptions, in which "experiencers report perceiving events that occurred beyond the normal range of the physical senses, events that they could not have perceived normally if they had been conscious" (p. 381). Cook, Greyson, and Stevenson explored several illustrative cases, some from the published literature on NDEs and others from their own files. Although the cases involved apparently veridical perceptions of NDErs, some of them were based on accounts of experiences that occurred many years before they were reported and written down. It was difficult to locate witnesses and medical records for some of the cases.

The most impressive case in their collection, and the one with the fewest problems with alternative explanations, is the last one they discussed, that of Al Sullivan (pp. 399-401). During bypass surgery, he saw his heart "on what appeared to be a small glass table" (p. 399). The most remarkable thing he saw was his surgeon "flapping his arms as if trying to fly" (p. 399). He told his cardiologist as soon as he was able to speak after the surgery. It turned out that the cardiac surgeon would habitually "flatten his palms against his chest and give instructions to his assistants by pointing with his elbows" (p. 400). This was done before he scrubbed in to maintain a sterile operating field. The surgeon, though reluctant to discuss Sullivan's experience, confirmed that he had that peculiar habit. It seems that Sullivan saw him do this when his chest was open, rather than before the surgery, for he remembered his open chest and the doctors working on his legs, a detail that surprised him. However, this does not preclude him having seen the surgeon flatten his palms against his chest just before surgery, remembering that detail, and combining that with his NDE experiences in his memory. Nevertheless, this case offers some evidence of veridical perception during an NDE.

The authors concluded that cases such as those they described offer evidence that is not conclusive, but "suggestive" of survival. The convergence of the three features presented above is particularly important, especially the paranormal perception. They concluded: "Veridical cases are important because they are the single most important kind of case that will enable us to decide whether normal physiological or psychological theories of NDEs (and OBEs) are sufficient" (p. 401). They criticized Blackmore's position that investigating such cases is a waste of time, and argued that reports of veridical experiences should be investigated. The more investigation, the better the reports. They also discussed experiments that can test veridical perception in NDEs, such as those 
involving objects out of a patient's sight, and thought that such experiments ought to be pursued, even though opposition by hospital staff have thus far hindered such experiments.

In a more recent paper by these same authors, Kelly (now using her married name), Greyson, and Stevenson (2000) appeared more impressed with the NDE evidence. In the later paper, they wrote that NDEs offer substantial, but not conclusive, evidence for the belief that consciousness survives death. They argued that while any single feature of an NDE may be explained in terms other than survival of death, the conjunction of three features make alternative explanations difficult. These features are:

enhanced mental processes at a time when physiological functioning is seriously impaired; the experience of being out of the body and viewing events going on around as from a position above; and the awareness of remote events not accessible to the person's ordinary senses. (p. 513)

Kelly, Greyson, and Stevenson used two cases as examples of the convergence of these three features: their case of Al Sullivan, alluded to above, and Sabom's case of Pam Reynolds, which I shall discuss below. Impressed with the evidence from both cases, the authors concluded that such evidence is "suggestive of the survival of consciousness after death" (p. 518). Nevertheless, they did not go as far as Habermas and Moreland, for they held that "near-death experiences can provide only indirect evidence of the continuation of consciousness after death" (p. 518, italics original), for the familiar reason that the persons experiencing them are only near death, and are not actually dead. That being the case, the authors concluded that "near-death experiences of the type we have described, together with other kinds of experiences suggesting survival after death ... provide convergent evidence that warrant our taking seriously the idea that consciousness may survive death" (p. 518).

I will argue below that the more moderate assessment of the evidence by writers such as Becker and Kelly, Greyson, and Stevenson, is correct: that NDEs are, at this stage, suggestive that there may be conscious experience after death, but do not yet offer convincing evidence, except for the person who actually has the experience. Before returning to this theme, I will now turn to physicalist critics who strongly deny that NDEs offer even "pointers" toward belief in life after death. 


\section{The Case That NDEs Provide No Evidence of Survival}

Physicalist accounts of NDEs deny that such experiences offer convincing evidence at all for life after death, holding that physiochemical processes in the brain are sufficient explanations for the phenomenon. Beginning with the work of Russell Noyes (1972; Noyes and Kletti, 1976), who argued that the mechanism behind NDEs is depersonalization, a psychological stress reaction to impending danger, a number of writers have proposed various physicalist explanations of NDEs. Some of these writers are not physicalists in an absolute sense, since they argue from a Christian tradition, but they are physicalists when it comes to their interpretation of NDE evidence. Stephen Vicchio (1979, 1980,1981 ) agreed with Noyes that NDEs are stress reactions, but added arguments based on his Christian convictions, writing that if there were proof of life after death, that belief would no longer be a matter of faith (Vicchio, 1979). He also held to a strict view that life after death will involve the resurrection of the body, not the existence of a disembodied soul after death, so that disembodied experience is impossible by definition.

Another proponent of this position, Edward Wierenga (1978), presented a similar position on the resurrection of the body and noted, as did Vicchio and Noyes, that NDErs are near death, but not actually dead. Of course, unlike Noyes, who critiqued NDEs from a physicalist position, Wierenga and Vicchio were not metaphysical materialists. But not every Christian interpreter of NDEs agrees with the conclusions of Vicchio and Noyes; even Habermas and Moreland, who as traditional Christians accept the idea of bodily resurrection, supported the idea that NDEs offer evidence, indeed strong evidence, for perceptual experience in a disembodied soul after death. I would suggest that Noyes, Vicchio, and Wierenga should also be open to evidence that suggests outof-body perceptual experience during NDEs, and that there is nothing wrong with altering one's metaphysical position if experience suggests it should be altered.

In a recent article that has been influential in the debate over whether NDEs are different in kind from drug-induced experiences, Karl Jansen (1997) modeled NDEs on brain receptors that respond to the drug ketamine. Jansen was clearly hostile towards the survivalist interpretation of NDEs: "NDEs are not evidence for life after death on simple logical grounds: death is defined as the final irreversible end" (p. 5). He also clearly accepted a philosophical naturalism, identifying the 
scientific point of view with a denial that a soul can rise from the body with any kind of sensory experience. Jansen noted that the administration of ketamine to subjects produces NDE-like experiences, including the tunnel experience, seeing a light, and experiencing a god-like being (p. 8). He argued that NMDA receptors, the binding sites blocked by ketamine in the cerebral cortex, may play a role in the NDE, in that ketamine-like substances manufactured by the body could block these same receptors during the stressful period near death, resulting in the perceptions associated with an NDE.

As impressive as analogies to drug-induced experiences may sound, they are not free of problems. First, just because drug-induced experiences are similar to some of the experiences associated with NDEs, it does not follow that they are the same type of experience as the NDE. No one would deny that experiences of a tunnel or seeing a bright light could occur in contexts other than the NDE, including hallucinations or drug-induced experiences. It may still be the case that there are features of NDEs that differ in important ways from hallucinations or drug-induced experiences. Fenwick (1997), for example, argued that ketamine-induced experiences lack the noetic quality found in NDEs: most people under the influence of ketamine do not believe that their experience was of real events, in sharp contrast to the strong noetic quality of the NDE. Fenwick also noted that one of the phenomena to which Jansen referred, temporal lobe seizures, tend to produce haphazard and disorganized experiences, in contrast to the clear vision of most NDEs. He correctly noted that Jansen had assumed that a scientific viewpoint on NDEs would imply a brain-based cause; but there are alternative explanations that might work better, but that Jansen did not consider.

Second, even if NDEs occur at least in part due to changes in brain physiology, this does not imply that only changes in brain physiology cause NDEs: there might be other explanatory paradigms that complement or even go beyond the brain physiology paradigm, without denying its importance. This would still be true even if changes in brain physiology related to NDEs are similar to changes that occur under the influence of psychotropic drugs. A good example of openness to multiple explanatory paradigms is found in the work of Morse, David Venecia, and Jerrold Milstein (1989), who argued for a neurophysiologic explanatory model for NDEs, in which "the core NDE is genetically imprinted and triggered by serotonergic mechanisms" (p. 45). But these authors did not limit the explanation of the NDE to serotonin levels; on the contrary, they suggested that while the area in the brain associated with 
NDEs may produce OBEs as a response to stress, "it is just as likely that such an area represents the seat of the soul, the area of our brain that serves as a trigger point for the release of the soul at death" (p. 51).

Of course the physicalist might appeal to Occam's razor and argue that an appeal to the soul would multiply explanations without adequate reason. But it could also be argued that the physicalist is dogmatically clinging to a single explanatory paradigm without being open to others; it seems that the debate is at an impasse. This is one reason why the reports of veridical perception during NDEs are so important. If it could be shown that certain perceptions during NDEs cannot be explained without perception outside the body, then this impasse would be broken and NDEs would be evidence that the soul can have perceptions outside the body near death, an important step in the case for some kind of existence of the soul after death.

Among the most sophisticated and powerful physicalist interpretations of NDE evidence are found among those who argue that NDEs are due to physiological changes near death, such as cerebral anoxia. A good example is Juan Saavedra-Aguilar and Juan Gómez-Jeria's model of the NDE "based on temporal lobe dysfunction, hypoxia/ischemia, stress, and neuropeptide/neurotransmitter imbalance" (1989, p. 205). Although these authors did not rule out other models to explain NDEs, they were clearly sympathetic to the physicalist camp. Another critic of the survivalist hypothesis, though not a complete skeptic on NDEs offering evidence of survival, is Krishnan (1985). Like Noyes, Krishnan believes that at least some NDEs are probably "biological mechanisms that help the experiencer survive" (1985, p. 21). As mentioned above, Krishnan is interested in whether the OBE is evidence of survival of death. He was impressed by the standard reductionist interpretations of OBEs, that "whatever veridical information the subject relates after the episode may be based on memories, educated guesses, perceptions made in a semiconscious state, and so on; that is, the NDEr visualizes this information in a vivid manner, but does not actually see" (p. 22).

Krishnan referred to the research of Georg von Bekesy $(1963,1967)$, who found that vibrators worn on one forearm caused a point perception, but when worn on both forearms "the point perception suddenly leaps into the space between them; that is, the subject feels that the perception of stimulation is occurring away from the receptor surface" (Krishnan, 1985, p. 24). Krishnan made the analogy to OBEs, arguing that they may be similar misperceptions of location caused by a similar brain mechanism. OBE-like sensations can occur in temporal lobe epilepsy as well. 
Krishnan also argued against OBEs being body-independent experiences by noting their similarity to our usual modes of consciousness. If the OBE is truly independent of the body's sense organs, then why can OBErs not perceive "various energy forms such as X-rays, ultrasonics, gamma rays, and so on" (p. 24)? The limitation of OBE perception to those forms of energy we normally experience would suggest that OBErs are not really out of the body. Krishnan noted that at the time he was writing (1985), there was not a case of a congenitally blind person having an OBE; but he also claimed that even if there were, our lack of knowledge of vision would prevent us from using such an experience as support for the survivalist interpretation of NDEs. Krishnan also referred to the cultural relativity of NDEs, and explored various psychological and physiological interpretations of NDEs, such as sensory deprivation, extrasensory perception, and protective emotions, which he thought were more convincing explanations than the survivalist hypothesis.

Not all critics of NDE evidence for survival are willing to reduce the NDE to just physiological processes in the dying body. Robert Kastenbaum (1996), for example, like other critics of NDEs as support for survival, noted that NDEs occur near death, not after death. He also discussed a number of other problems with the NDE evidence: why more people near death do not report NDEs, why some NDEs are frightening and others peaceful, why some people not near death have NDE-like experiences, and why individuals very close to death may actually be "less likely to report an NDE than those who were less endangered" (p. 261). But Kastenbaum is not a reductionist in the sense that he believes that a physicalist explanation of NDEs exhausts its value or meaning. Rather, he supports a phenomenological approach to NDEs, focusing on the experience as a whole and its functional value. Still, he remains skeptical when it comes to NDEs offering evidence of life after death.

The critics mentioned thus far have made some significant inroads against the strength of the NDE case for survival. However, physicalist hypotheses must be backed up by studies that correlate NDEs with the physiological causes proposed by critics such as Saavedra-Aguilar and Gómez-Jeria and Krishnan. The lucidity of NDEs as opposed to the experiences to which critics compare NDEs, such as drug-induced, anoxic, or hallucinatory experiences, must be considered (Sabom, 1998). In addition, such physicalist explanations must also contend with evidence for veridical perception during NDEs (Sabom, 1982, 1998), evidence which, at the very least, should throw doubt upon the physicalist explanation of the NDE evidence. A physicalist explanation should not 
be held dogmatically on the basis of a prior metaphysical view of the world that is not amenable to change from empirical evidence. To assert in advance that empirical evidence can only imply a physicalist interpretation simply begs the question. And though Kastenbaum was not opposed to scientific study of the NDE, he preferred a phenomenological approach to NDEs and seemed more interested in that approach than the exploration of NDE evidence for life after death.

But the issue of life after death is the most profound issue raised by NDEs, for if they do offer considerable evidence for survival of death, such evidence could profoundly shake our view of reality as a whole. As interesting and helpful as a phenomenological approach to NDEs is, especially in its nonreductionism, it ignores important metaphysical issues, such as life after death, that should be explored. As for the claim of Kastenbaum and others that NDErs were not really dead because death is by definition irreversible, I grant this, but I deny that this makes NDE evidence irrelevant to the issue of life after death. Habermas and Moreland's fourth line of evidence, from NDErs who had encounters with people they had known in life but did not know had died, is clearly relevant to the afterlife hypothesis.

One of the most profound and carefully argued critiques of the survivalist interpretation of NDEs was Blackmore's (1993). Despite her clear physicalist presuppositions, Blackmore was quite respectful of the NDE phenomenon, holding that such experiences can have great psychological value and can even play a healthy, life-transforming role in an individual's life. However, she did not believe that they provide strong evidence for life after death, since all of the reported phenomena associated with NDEs can be explained in terms of the physiological processes related to lack of oxygen to the brain.

In her detailed and technical case, Blackmore addressed specifics of how changes in brain physiology could cause the typical experiences associated with NDEs, such as peace, bodily separation, moving through a tunnel, and seeing dead relatives or religious figures. Her detailed criticism of Sabom's study is important, since Sabom's belief that his patients presented accurate information about their resuscitations that they could not have known otherwise is a key link in the chain of arguments presented by those who believe that NDEs offer real evidence for life after death. Blackmore argued that the details Sabom's patients presented concerning their resuscitations could have been gained in a number of ways that did not imply separation of the self from the body or any form of life after death. She wrote that prior knowledge and expectations of cardiopulmonary resuscitation (CPR) played a role in 
creating "memories" of the experience. Without the details of the resuscitation in the medical records, which often leave out the specific details of procedures used, there is no accurate way to check a patient's account to determine whether it is accurate. Also, some NDErs were interviewed years after their resuscitation, and that is more than enough time for these patients to learn about the specifics of CPR, especially since they were resuscitated and might be interested in learning about the procedures used.

Blackmore also critiqued Sabom's control group of patients who had not experienced NDEs: as she correctly pointed out, most of those patients had not suffered a cardiac arrest and resuscitation, and therefore would be less likely to reconstruct the event from details overheard during the resuscitation. Individuals tend to form visual images of things they hear; when most people hear a story, they form concrete mental images of the details. Blackmore gave the example of a story of a cat crossing in front of people walking in the woods; individuals who hear the story form concrete mental images of a particular cat of a particular color and size, and of the specific appearance of the woods and the sky. The same thing could be happening in NDEs: those who are resuscitated may hear things during the resuscitation or after the resuscitation, and then construct mental images of the details, which are then "remembered." Blackmore went on to note that in cases of "distant vision" that seem to preclude such reconstruction, the reports of the NDEr are usually not specific enough to warrant belief in visual experience, such as a boy who noticed that his two dead grandfathers had brown and black hair. But as Blackmore pointed out, brown and black are very broad descriptions of a wide range of hair colors.

She also claimed that the seemingly impressive reports of blind patients reporting NDEs are not as impressive as they appear; at the time she wrote (in 1993), there were no confirmed cases of visual out-of-body experiences in patients congenitally blind. Those not blind from birth can construct mental images from what they have heard, similar to people with normal vision. (There have since been reports of congenitally blind individuals who report visual perception in NDEs [Ring and Cooper, 1997].) Blackmore concluded that, since all evidence purported to support an out-of-body interpretation of NDEs is inadequate, and since there is an adequate physiological explanation for NDE phenomena in cerebral anoxia, she saw "no reason to adopt the afterlife hypothesis" (p. 263).

Blackmore mounted powerful arguments against the position that NDEs can be used to make a strong case for life after death. This does 
not mean, however, that no such case could be made. If Sabom's control group had consisted only of patients who had experienced cardiac arrest without an NDE, and if the NDErs had specific, detailed knowledge of CPR that the control group did not, this would provide considerable evidence for the position that NDErs gained their information from the NDE itself. If there were cases of NDEs in which patients recalled visual information that could only been learned by actually being outside the body, such as recalling specific details of the clothing worn by the code team, specific details of the resuscitation including the order of events, or details of the room in which the resuscitation occurred that could have only been learned by actually being there, then this would support the out-of-body interpretation of NDEs, which could then be used as evidence of a "minimalist life after death." If reports of NDErs seeing those whom they did not know were dead turn out to fit the facts of the case, then this would seem to mark some evidence of continuation of life beyond biological death. It is thus possible that NDEs could be used to make a strong case for a "minimalist" life after death; but such evidence is lacking at present. At the end of this paper, I shall discuss a recent experiment that offers a promising direction towards research in this area.

\section{The Case That NDEs Provide Strong of Survival for the Experiencer}

How much support does the present NDE evidence, then, actually lend in favor of life after death? For most of us, the answer is "some evidence that should be taken seriously and further researched, but not conclusive evidence." It is too ambiguous to support Habermas and Moreland's position that NDEs offer strong evidence for a minimalist life after death. On the other hand, Blackmore and other physicalists tend to dismiss out-of-hand the notion that NDEs could offer evidence in favor of life after death. I suggest that the truth is a middle way between the extremes: contrary to the physicalist position, NDEs do offer some evidence for survival of death that should be taken seriously; and contrary to Habermas and Moreland's position, it is not yet substantial or convincing evidence, at least for most of us.

However, there is a group of people who have rational justification in taking NDEs to be strong, and even convincing, evidence of life after death. I argue that NDEs can offer reasonable evidence for life after death for the individual NDEr. Now one might claim that this is 
absurd: how can one group of people rationally take NDEs to be strong evidence of life after death, while the rest of us are not so rationally justified? Actually, such epistemic situations are very common, in which some persons are justified in taking certain evidence as compelling a certain conclusion, while other persons are not so justified. The following example makes this clear. If I see a bear in the woods in an area in which bears are not know to exist, given normal vision, a clear day, and good health, I am rational in taking that experience as convincing evidence that a bear is in the woods. But though it would offer some evidence for others that a bear is in the woods, it does not constitute strong or convincing evidence for them, especially since, in this scenario, no bears were known previously to live in the woods. Other people would need further evidence to conclude rationally that there is a bear in the woods, such as verified reports of more bear sightings or verified bear tracks.

I believe that the NDE evidence for life after death is a similar situation; but one must be careful here. NDEs have a "noetic quality"; often, the experiencers believe without any doubt that they have separated from the body and experienced life after death. But a person's absolute conviction that he or she has experienced an event does not mean that the claimed event was actually the cause of the experience. Experience, even sensory experience, requires interpretation; experience is experiencing as. For example, I have a photograph that apparently shows trees in the woods under a clear sky. Almost every individual who sees the photograph is absolutely certain that that is what he or she is experiencing. In order to foster that certainty when I show the photograph to my philosophy students, I turn it upside down; for it is a photograph of the reflection of trees and sky in clear water. The noetic quality of the students' perceptual experience, their absolute certainty, that they were observing a photograph of trees and sky, and not a photograph of a reflection in water, did not make their perception correct (Proudfoot, 1996). The same is true for the persons who have NDEs. Their absolute certainty that the experience was one of their disembodied soul separated from the body, along with the sense of being dead, does not mean that they literally experienced these things.

But there is more to be said. Suppose that a patient suffers a cardiac arrest, has an NDE, and talks to the physician about it soon afterwards (and not years later as in some cases). The individual recalls in detail the process of resuscitation, including who was present, the clothes they were wearing, and the specific layout of the room. Suppose that every detail is correct and is confirmed by the physician and the other 
members of the medical staff involved in the resuscitation. Let us further suppose that during the NDE, the patient sees his or her father and brother and is surprised to see them; they tell the NDEr that they are now dead and in another world. Later, after the resuscitation, the patient discovers that his or her father and brother were killed in a traffic accident hours before the cardiac arrest, and he or she had not been informed of that. Would this patient be justified in believing that the NDE offers strong evidence for life after death? I think we have to reply that such a patient would be rational in believing that the NDE offered strong evidence for life after death-for that individual. By itself, it would not offer strong evidence for everyone else; a report of the incident would become another anecdotal case, though if carefully studied it could be combined with other cases in a large-scale study of NDEs.

There is, in fact, a case that, though not quite as impressive as the hypothetical example just mentioned, remains quite remarkable: that of Pam Reynolds, a 35-year-old woman with a giant basilar artery aneurysm (Sabom, 1998). In order to remove the aneurysm safely, surgeons performed a remarkable surgical procedure: "This operation... would require that her body temperature be lowered to 60 degrees, her heartbeat and breathing stopped, her brain waves flattened, and the blood drained from her head" (Sabom, 1998, p. 37). During the course of the surgery, Reynolds had a very detailed NDE, at first autoscopic and then transcendental. What is remarkable is how well her description of the experience correlated with the stages of her surgery. As her surgery began and her skull was being opened, she felt herself pulled out of her body through her head and, like many NDErs, felt that her awareness and vision were the most acute she had ever experienced. She accurately described her head being shaved and the instrument used to cut open her skull. During her surgery, due to the small size of her right femoral artery and vein, her left femoral artery and vein were connected to the heart-lung machine. A female cardiac surgeon made that decision, and Reynolds recalled hearing a female voice saying that her veins and arteries were small. It is important to note that during this part of the surgery, Reynolds' heart was still beating, and she was not clinically dead.

The next part of her surgery involved inducing clinical death. Her body was cooled and, as a result, her heart went into ventricular fibrillation; eventually it was stopped completely by a potassium chloride injection. Her EEG became flat, and even brainstem activity, tested by a response to clicks emitted from speakers in her ears, could no longer 
be detected. Her body temperature reached the 60 degrees required for the surgery to take place, her blood was drained from her body, and the aneurysm was removed. Her blood was returned to her body and her body temperature raised. Brainstem activity returned, shown by a response when the speakers in her ears clicked, followed by the higher brain activity detected by the EEG. Her heart began fibrillating and returned to a normal sinus rhythm after two shocks from a defibrillator. Her surgery was a success.

It was during that time that Reynolds had the transcendental portion of her NDE. Since this did not involve an experience of the operating theater, it is not easy to correlate her experiences with specific points in her surgery. In many ways, her experience was typical of transcendental experiences: she felt herself "pulled," though she said that her sensation "wasn't a bodily, physical sensation"; traveling through something that "was like a tunnel but wasn't a tunnel" (p. 44), and she reported a heightened sense of hearing. At the end of the tunnel was a bright light, and she saw beings of light, which included her grandmother and other deceased relatives. They did not permit her to go further, and although she wanted to go "into the light," she realized she had a family to raise and wanted to go back as well. An interesting part of her experience was when the dead relatives were "feeding" her with something she described as "sparkly." When it was time for her to return to her body, her uncle led her, even though she did not want to go. She mentioned that she saw "the thing, my body." Her uncle "communicated" to her that coming back into her body was "like jumping into a swimming pool." She still did not want to go, but eventually her uncle pushed her, and she said that coming back into her body "hurt." She described accurately the music playing near the end of her surgery as she was being closed up (pp. 44-47).

Sabom had earlier found that NDEs are more likely the closer a person comes to death, and he recognized that many of these NDErs were clinically dead, but not actually dead. Reynolds' case caused him to reconsider his belief that NDEs do not occur after actual death. Reynolds met all the criteria for death based on clinical tests, including a flat EEG, lack of auditory evoked potentials, and lack of blood flow to the brain. (For those who do not accept brain death criteria and prefer circulatory-respiratory criteria, one could note that there was no circulation of blood, and indeed no blood, in her body during the deep hypothermic portion of her surgery.) It was during this part of her surgery that Reynolds had a deep NDE that scored 27 on Greyson's (1983) NDE scale, on which the average score for NDEs is 15, the deepest 
of all the subjects in Sabom's study of NDEs. Yet Sabom did not go to the point of saying she was dead, insisting (I think correctly) that physicians cannot raise people literally from the dead. He also noted that many people who are certified as brain dead retain hypothalamic and other brain functions, so it is possible that some activity was still going on in Reynolds' brain. In the end, Sabom held that, consistent with the belief that death is a process, the NDE is a state in which "the person's spirit or soul is in the process of separation from the body" (p. 203). His studies of NDEs have convinced him that they are genuine spiritual experiences, not hallucinations caused by drugs or anoxia.

The Reynolds case is remarkable not only for its depth and the accuracy of Reynolds' recall of her surgery, but also for the degree of correlation between her descriptions of her experience and the physiological state she was in at the time. Physicalist explanations do not explain this case. For example, Kelly, Greyson, and Stevenson (2000) noted that the experiences of Reynolds (and Al Sullivan; see above) cannot be explained in terms of auditory input, because they were clearly visual in nature; in addition, Reynolds' ears were blocked during the surgery. Although one cannot be totally certain of the timing, she reported some experiences that occurred during total cardiopulmonary arrest and during a total lack of brain function. Certainly she is rational in taking her experience to be one of extrabodily perception and, given her vision of dead relatives, of some minimal life after death. For her, then, the NDE offers convincing evidence for survival of death, and she is rational in taking it as such. It strengthens the public case for life after death as well, but it remains only one remarkable case. It does not offer, by itself, convincing public evidence for life after death.

This does not imply that every person who experiences an NDE and interprets it as evidence of life after death is rational in doing so. There may be obvious physiological factors involved in some NDEs: some may be caused solely by cerebral anoxia or by reactions to drugs. The experiences themselves may not cohere: rambling, dreamlike accounts of NDEs would be suspect. The experiences may not fit reality: if someone recalls a resuscitation that did not take place, or while being resuscitated saw a vision of a "dead" relative who turned out to be very much alive, it is unlikely that the experience was one of the afterlife. If the experience is internally coherent, and the recall of sensory experience cannot be easily explained without bringing into play some kind of out-of-body perception, then the NDEr would be rational in holding 
at least to a dualistic interpretation of the experience, though not necessarily a belief in life after biological death. If the NDE includes experiences of those who are biologically dead, and such experiences are not easily explained without positing some communication with those individuals who have actually died, the NDEr is rational in accepting some kind of experience after biological death. To say that such positions are always irrational is to rule out by definition the possibility of disembodied experience after death; Blackmore seemed close to doing this herself in her critique of the survivalist interpretation of NDEs. But if one does not rule out by definition such experiences after death, then the individual NDEr, in some cases, is reasonable in taking his or her experience to be strong evidence for life after death.

Whether a strong case can be developed for life after death from NDEs for the rest of us remains to be seen. What is needed is research along the lines suggested by Badham and Badham, studies that test for evidence of veridical perception during NDEs, and in which the subjects' experiences are carefully coordinated with their physiological state at the time of cardiac arrest. Sabom's two studies $(1982,1998)$ correlated the physiological status of the subjects with the times of their NDE experience, and he explored the possibility of veridical perception by correlating the patients' reported experiences during an autoscopic NDE with their medical records.

Another recent study, though relatively small, could be used as a model for further research in this area. Parnia, Waller, Yeates, and Fenwick (2001) studied a group of 63 cardiac arrest survivors who showed no sign of confusion, to determine whether they had any memories of the time they were in arrest, evaluating their reports based on Greyson's NDE Scale. They documented levels of blood oxygen and carbon dioxide, as well as sodium and potassium, during the arrest period, and asked patients about their religious backgrounds and level of religious practice. To test for veridical perception during the NDE, "boards were suspended from the ceiling of the wards prior to the commencement of the study. These had various figures on the surface facing the ceiling which were not visible from the floor" (p. 151).

Seven of the 63 patients ( 11 percent) reported some memories of the time of their cardiac arrest, and four of these ( 6 percent) had NDEs. All four NDErs had a sense of arriving at some kind of "border" or point of no return; three of the four reported seeing a bright light and feelings of peace and joy; two of the NDErs reported seeing deceased relatives; and two reported a feeling of heightened sensation. Oxygen levels were 
actually higher in the NDErs than in nonexperiencers. The authors believed that such memories during times of cardiac arrest in patients with normal oxygen saturation should at least encourage researchers to consider the implications of NDEs for the mind-brain relationship. Because no OBEs occurred among the NDErs in the study, there was no opportunity to test veridical out-of-body perception. Still, this study offers a framework for others that can be repeated elsewhere. As the authors of this study concluded: "For an adequate prospective sample to be collected so that both the psychological (including out of body experiences) and physiological aspects of the experiences can be looked at in detail, a multi-centre trial is needed" (p. 155). I can only agree with his conclusion and hope that further studies are forthcoming on the value of NDE evidence for belief in life after death.

\section{References}

Badham, P., and Badham, L. (1982) Immortality or extinction? Totowa, NJ: Barnes and Noble.

Becker, C. B. (1993). Paranormal experience and survival of death. Albany, NY: State University of New York Press.

Becker, C. B. (1995). A philosopher's view of near-death research. Journal of Near-Death Studies, 14, 17-25.

Blackmore, S. (1993). Dying to live: Near-death experiences. Buffalo, NY: Prometheus Books.

Cook, E. W., Greyson, B., and Stevenson, I. (1998). Do any near-death experiences provide evidence for the survival of human personality after death? Relevant features and illustrative case reports. Journal of Scientific Exploration, 12, 377-406.

Fenwick, P. (1997). Is the near-death experience only N-methyl-D-aspartate blocking? Journal of Near-Death Studies, 16, 43-53.

Greyson, B. (1983). The Near-Death Experience Scale: Construction, reliability, and validity, Journal of Nervous and Mental Disease, 171, 269-275.

Habermas, G. R., and Moreland, J. P. (1992). Immortality: The other side of death. Nashville, TN: Thomas Nelson.

James, W. (1958). The varieties of religious experience. New York, NY: Mentor Books. (Original work published 1902 .)

Jansen, K. L. R. (1997). The ketamine model of the near-death experience: A central role for the N-methyl-D-aspartate receptor. Journal of Near-Death Studies, 16, 5-26.

Kastenbaum, R. (1996). Near-death reports: Evidence for survival of death? In L. W. Bailey and J. Yates (Eds.), The near-death experience: A reader (pp. 247-264). New York, NY: Routledge.

Kelly, E. W., Greyson, B., and Stevenson, I. (2000). Can experiences near death furnish evidence of life after death? Omega, 40, 513-519.

Krishnan, V. (1985). Near-death experiences: Evidence for survival? Anabiosis: The Journal of Near-Death Studies, 5(1), 21-38.

Kübler-Ross, E. (1976, August). When face to face with death [Interview]. Reader's Digest, pp. 81-84.

Lorimer, D. (1984). Survival? Body, mind and death in the light of psychic experience. London, England: Routledge and Kegan Paul. 
McCullagh, P. (1993). Brain dead, brain absent, brain donors: Human subjects or human objects. Chichester, England: Wiley.

Moody, R. A. (1975). Life after life. Covington, GA: Mockingbird Books.

Morse, M., Venecia, D., and Milstein, J. (1989). Near-death experiences: A neurophysiologic explanatory model. Journal of Near-Death Studies, 8, 45-53.

Morse, M., and Perry, P. (1990). Closer to the light: Learning from the near-death experiences of children. New York, NY: Villard.

Noyes, R. (1972). The experience of dying. Psychiatry, 35, 174-184.

Noyes, R., and Kletti, R. (1976). Depersonalization in the face of life-threatening danger: A description. Psychiatry, 39, 19-27.

Owens, J. E., Cook, E. W., and Stevenson, I. (1990). Features of "near-death experience" in relation to whether or not patients were near death. Lancet, 336, 1175-1177.

Parnia, S., Waller, D. G., Yeates, R., and Fenwick, P. (2001). A qualitative and quantitative study of the incidence, features, and aetiology of near death experiences in cardiac arrest survivors. Resuscitation, 48, 149-156.

Penfield, W., and Rasmussen, T. B. (1950). The cerebral cortex of man. New York, NY: Macmillan.

Proudfoot, W. (1996). Religious experiences as interpretative accounts. In M. Peterson, W. Hasker, B. Reichenbach, and D. Basinger (Eds.), Philosophy of religion: Selected readings (pp. 30-40). New York, NY: Oxford University Press.

Rawlings, M. (1980). Before death comes. Nashville, TN: Thomas Nelson.

Ring, K., and Cooper, S. (1997). Near-death and out-of-body experiences in the blind: A study of eyeless vision. Journal of Near-Death Studies, 16, 101-147.

Saavedra-Aguilar, J. C. and Gómez-Jeria, J. S. (1989). A neurobiological model for neardeath experiences. Journal of Near Death Studies, 7, 205-222.

Sabom, M. (1982). Recollections of death: A medical investigation. New York, NY: Harper and Row.

Sabom, M. (1998). Light and death: One doctor's fascinating account of near-death experiences. Grand Rapids, MI: Zondervan.

Vicchio, S. J. (1979). Against raising hope of raising the dead: Contra Moody and KüblerRoss. Essence, 3, 51-67.

Vicchio, S. J. (1980). Moody, suicide, and survival: A critical appraisal. Essence, 4, 69-77.

Vicchio, S. J. (1981). Near-death experiences: Some logical problems and questions for further study. Anabiosis: The Journal of Near-Death Studies, 1, 66-87.

von Bekesy, G. (1963). Interaction of paired sensory stimuli and conduction in peripheral nerves. Journal of Applied Physiology, 18, 1276-1284.

von Bekesy, G. (1967). Sensory inhibition. Princeton, NJ: Princeton University Press.

Wierenga, E. (1978). Proving survival? Reformed Journal, 28, 26-29. 